\section{RISK FACTORS ASSOCIATED WITH BRONCHOPULMONARY DISPLASIA (BPD) IN EXTREMELY LOW GESTATIONAL AGE NEWBORNS (ELGAN)}

A.M. Sánchez Torres ${ }^{1}$, M.D. Elorza Fernández', J. Pérez Rodriguez ${ }^{1}$, A. Díaz Redondo², J. Quero Jiménez ${ }^{1}$

${ }^{1}$ Neonatology, ${ }^{2}$ Statistics, La Paz University Hospital, Madrid, Spain

Aims: To analyse influence of perinatal data and early morbidity on moderate-severe BPD in ELGAN with birth weight $(B W)<1000 \mathrm{~g}$.

Methods: This is a retrospective cohort of all ELGAN with $B W<1000 \mathrm{~g}$ alive at $36 \mathrm{w}$ postmenstrual age born between 2004-2009 in our unit. BPD was defined as moderate-severe following NICHDNHLBI workshop definitions.

Results: 201 infants were included. Moderatesevere BPD prevalence was $41.7 \%$. BPD group had lower gestational age(GA) and BW(25.5 \pm 1.1 vs $26.2 \pm 1 \mathrm{w} p=0.000 ; 749 \pm 123.3$ vs $830.4 \pm 116.7 \mathrm{~g}$ $p=0.000)$ and higher rate of male sex(59.5 vs $47 \% p=0.039)$ and vaginal delivery(45.2 vs $22.7 \%$ $\mathrm{p}=0.012$ ). We didn't find differences in antenatal steroids or chorioamnionitis. BPD patients needed more delivery room intubation(75 vs $55.5 \%$ $p=0.006)$, higher oxygen $(0.52 \pm 0.24$ vs $0.41 \pm 0.21$ $p=0.000)$ and had lower initial PEEP $(4.2 \pm 0.6$ vs $\left.4.4 \pm 0.6 \mathrm{H}_{2} \mathrm{Ocm} p=0.01\right)$. They had higher rates of RDS, early hypotension, symptomatic PDA and PDA requiring surgery $(86.9$ vs $76 \% p=0.044 ; 60.7$ vs $27.3 \% p=0.000 ; 66.6$ vs $56.4 \% p=0.000 ; 46.4$ vs $11.9 \% \mathrm{p}=0.000)$. In BPD group Ureaplasma urealitycum bronchopneumonia was higher without significance(19 vs $6.8 \% p=0.06)$. Late sepsis and pneumonia( 76.1 vs $58.9 \%$ p $=0.000 ; 70.2$ vs $18.8 \%$ $\mathrm{p}=0.000$ ), severeHIVandhemorrhagicperiventricular infarction rates were more frequent( 8.3 vs $1.7 \%$ $p=0.000 ; 5.9$ vs $1.7 \% p=0.000$ ).

More days on mechanical ventilation and oxygen therapy were observed in BPD group(29.8 \pm 20.5 vs $11.2 \pm 12.9 \mathrm{p}=0.000 ; 102.2 \pm 29.8$ vs $47.2 \pm 20.8$ $p=0.000 ; 6.6 \pm 7.1$ vs $3 \pm 2.8 p=0.001$ ).

Conclusion: Low GA and BW, male sex, early respiratory morbidity, respiratory infection, symptomatic PDA are risk factors for BPD in ELGAN. Could we design new strategies controlling these factors to prevent BPD development?

\section{RSV INFECTION IN INFANTS ADMITTED TO PAEDIATRIC INTENSIVE CARE UNIT}

A. López Escobar, M. Fernández Díaz, S. Jimeno Ruiz, I. Llana Martín, M. Benedit Gómez, Comisión de Investigación y Actualización Neonatal

Departamento de Pediatría. Hospital Universitario de Madrid Torrelodones, Universidad San Pablo CEU, Madrid, Spain

Objectives: Description of RSV infection in infantes below two months old admitted to Paediatric Intensive Care Unit (PICU).

Methods: Descriptive and retrospective study of infants less than two months old admitted to PICU with the diagnosis of RSV infection from january-2004 to December-2010.

Results: 53 children below two months of age were admitted to PICU hospital during the period of study with diagnosis of RSV infection. 25 from the emergency department and 28 from the paediatric floor. The causes of admission were apnoea (in $21,4 \%$ of the cases) and respiratory distress (in $78,6 \%$ of the cases). $30,1 \%$ of these children were preterm.

$94,3 \%$ of the infants admitted developed bronchiolitis, $17 \%$ presented apnoea. $76,9 \%$ were treated with epinefrine and $32,7 \%$ with albuterol. $26,4 \%$ required antibiotics.

Ventilatory assistance was needed in $65 \%$ of the patients (CPAP in $50 \%$ and ventilatory support in $15 \%)$.. They required a mean $\mathrm{FiO} 2$ of $30.8+/-16.1 \%$ for a period of $3.85+/-3.54 d$. Mean $\mathrm{PCO} 2$ was $57.4+/-14 \mathrm{mmHg}$. A chest $\mathrm{X}$-ray was performed in $75.5 \%$ of the children and showed pneumoniae or atelectasia in $43,2 \%$ of the cases.

Discussion: Patients with a diagnosis of RSV infection admitted to PICU develope bronchiolitis in a high percentage. Epinefrine was the main treatment used. Mainly $50 \%$ of these infants required respiratory assistance. 